\title{
Exposure to Cerium Oxide Nanoparticles Is Associated With Activation of Mitogen-activated Protein Kinases Signaling and Apoptosis in Rat Lungs
}

\author{
Kevin M. Rice ${ }^{1-4}$, Siva K. Nalabotu ${ }^{1,5}$, Nandini D.P.K. Manne', Madhukar B. Kolli ${ }^{1,5}$, Geeta Nandyala ${ }^{1}$, Ravikumar Arvapalli', \\ Jane Y. Ma ${ }^{6}$, Eric R. Blough ${ }^{1-7}$ \\ ${ }^{1}$ Center for Diagnostic Nanosystems, Marshall University, Huntington, $W V_{;}^{2}$ School of Kinesiology, College of Health Professions, Marshall University, \\ Huntington, WV; ${ }^{3}$ Biotechnology Department, West Virginia State University, Institute, WV; ${ }^{4}$ Department of Internal Medicine, Joan C. Edwards \\ School of Medicine, Marshall University, Huntington, WV; ${ }^{5}$ Department of Pharmacology, Physiology and Toxicology, Marshall University, Joan C. \\ Edwards School of Medicine, Huntington, WV; ${ }^{6}$ Health Effects Laboratory Division, NIOSH, Morgantown, WV; ${ }^{7}$ Department of Pharmaceutical Sciences, \\ Marshall University School of Pharmacy, Huntington, WV, USA
}

Objectives: With recent advances in nanoparticle manufacturing and applications, potential exposure to nanoparticles in various settings is becoming increasing likely. No investigation has yet been performed to assess whether respiratory tract exposure to cerium oxide $\left(\mathrm{CeO}_{2}\right)$ nanoparticles is associated with alterations in protein signaling, inflammation, and apoptosis in rat lungs.

Methods: Specific-pathogen-free male Sprague-Dawley rats were instilled with either vehicle (saline) $\mathrm{or}^{\mathrm{CeO}_{2}}$ nanoparticles at a dosage of $7.0 \mathrm{mg} / \mathrm{kg}$ and euthanized 1, 3, 14, 28, 56, or 90 days after exposure. Lung tissues were collected and evaluated for the expression of proteins associated with inflammation and cellular apoptosis.

Results: No change in lung weight was detected over the course of the study; however, cerium accumulation in the lungs, gross histological changes, an increased Bax to $\mathrm{Bcl}-2$ ratio, elevated cleaved caspase-3 protein levels, increased phosphorylation of p38 MAPK, and diminished phosphorylation of ERK-1/2-MAPK were detected after $\mathrm{CeO}_{2}$ instillation $(p<0.05)$.

Conclusions: Taken together, these data suggest that high-dose respiratory exposure to $\mathrm{CeO}_{2}$ nanoparticles is associated with lung inflammation, the activation of signaling protein kinases, and cellular apoptosis, which may be indicative of a long-term localized inflammatory response.

Key words: Cerium oxide nanoparticles, Lung, Inflammation, Mitogen-activated protein kinases

Received: January 30, 2015 Accepted: April 22, 2015

Corresponding author: Kevin M. Rice, MS

Room \#241 D, 1700 3rd Avenue, Huntington, WV 25755-1090, USA

Tel: +1-304-638-2982, Fax: +1-304-696-3766

E-mail: rice9@marshall.edu

This is an Open Access article distributed under the terms of the Creative Commons Attribution Non-Commercial License (http://creativecommons.org/licenses/by$\mathrm{nc} / 3.0 / /$ which permits unrestricted non-commercial use, distribution, and reproduction in any medium, provided the original work is properly cited.

\section{INTRODUCTION}

Cerium is a lanthanide metal that can undergo redox cycling depending on the partial pressure of oxygen in the surrounding environment [1]. The industrial production and utilization of cerium oxide $\left(\mathrm{CeO}_{2}\right)$ nanoparticles is increasing rapidly in the polishing, energy, electronic, automobile, and biomedical industries [2]. Recently, $\mathrm{CeO}_{2}$ nanoparticles have been used as catalysts in combustion engines to reduce particulate emis- 
sions and increase fuel efficiency [3]. Other work has demonstrated that $\mathrm{CeO}_{2}$ nanoparticles may exhibit antioxidant activity [4], which has led to the suggestion that these particles may be useful for the treatment of cardiovascular disease [5], neuronal injury [6], and the prevention of radiation-induced damage [7].

In addition to the beneficial applications of $\mathrm{CeO}_{2}$ nanoparticles, some researchers have begun to examine whether these materials may also be toxic. In vitro studies using lung cancer cells (A549) [8] and bronchoalveolar epithelial cells (BEAS2B) [9] have suggested that cellular exposure to $\mathrm{CeO}_{2}$ nanoparticles may be associated with the increased production of reactive oxygen species and the induction of cellular apoptosis. Other work using intact rats has demonstrated that exposure to $\mathrm{CeO}_{2}$ nanoparticles can cause lung inflammation and fibrosis [1012]. How exposure to $\mathrm{CeO}_{2}$ nanoparticles may induce lung inflammation and remodeling has not been fully elucidated.

Mitogen-activated protein kinases (MAPKs), including the extracellular signal-regulated kinase (ERK)-1/2-MAPK, p38 MAPK, and c-Jun amino terminal kinase (JNK), are a family of serine/ threonine-specific kinases that transduce extracellular stimuli and are involved in the regulation of cell proliferation, gene expression, and apoptosis $[13,14]$. Previous work has suggested that several metals, including arsenic, zinc, and chromium, can induce the phosphorylation of MAPK proteins [15]. To the best of our knowledge, no studies have yet investigated whether exposure to $\mathrm{CeO}_{2}$ nanoparticles can elicit similar activity.

The primary goal of this study was to determine if exposure to $\mathrm{CeO}_{2}$ nanoparticles is associated with the activation of MAPK signaling and cellular apoptosis in the lungs of intact rats. Our data suggest that exposure to $\mathrm{CeO}_{2}$ nanoparticles is associated with cerium accumulation in the lungs, an increased $\mathrm{Bax}$ to $\mathrm{Bcl}-$ 2 ratio, elevated caspase-3 protein levels, increased phosphorylation of p38 MAPK, and diminished phosphorylation of ERK$1 / 2$-MAPK $(p<0.05)$. Taken together, these data suggest that exposure to $\mathrm{CeO}_{2}$ nanoparticles is associated with activation of MAPK signaling along with cellular apoptosis.

\section{METHODS}

\section{Particle Characterization}

$\mathrm{CeO}_{2}$ nanoparticles with an average hydrodynamic diameter of approximately $20 \mathrm{~nm}$ and average physical diameter of approximately $10 \mathrm{~nm}$ were obtained from Sigma-Aldrich (St. Louis, MO, USA), corresponding to the specifications of nanoparticles used in previous experiments [12]. Normal saline was used to suspend the nanoparticles prior to instillation. Diluted particle suspensions were filtered, sputter-coated, and examined with a Hitachi Model S-4800 Field Emission scanning electron microscope (Schaumburg, IL, USA) at $5 \mathrm{kV}$ and $20 \mathrm{kV}$, or placed on a formvar-coated copper grid to dry and imaged with a JEOL 1220 transmission electron microscope (Tokyo, Japan), as previously described [16].

\section{Animal Handling and Instillation of Cerium Oxide Nanoparticles}

All procedures were performed in accordance with the Marshall University Animal Care and Use Committee guidelines, using the criteria outlined by the Association for Assessment and Accreditation of Laboratory Animal Care (AAALAC). Five-weekold (150 to $174 \mathrm{~g}$ ) specific-pathogen-free male Sprague-Dawley (Hla: SD-CVF) rats were purchased from Hilltop Lab Animals, Inc. (Scottdale, PA, USA). Rats were housed two per cage in an AAALAC-approved vivarium with a 12-hour light-dark cycle and maintained at $22 \pm 2^{\circ} \mathrm{C}$. Animals were allowed access to food and water ad libitum. All animals were allowed to acclimatize for two weeks before the study began. All animals were examined for precipitous weight loss, failure to thrive, or unexpected gait. Periodic weight measurements were taken throughout the duration of the study.

After acclimatization, the animals were randomly divided into 12 groups ( $n=6$ per group). After anesthetization, the animals were placed on an inclined restraint board and instilled with $0.3 \mathrm{~mL}$ of a saline suspension of $\mathrm{CeO}_{2}$ nanoparticles at a dosage of $7.0 \mathrm{mg} / \mathrm{kg}$ or $0.3 \mathrm{~mL}$ of saline, as described elsewhere [16]. This dose was selected based on previously published data by Ma et al. [17] demonstrating a dose-dependent response in lung cells.

\section{Tissue Collection}

Rats were anesthetized at $1,3,14,28,56$, or 90 days post-exposure, using a ketamine $(40 \mathrm{mg} / \mathrm{kg})$ and xylazine $(10 \mathrm{mg} / \mathrm{kg})$ cocktail (administered intraperitoneally), supplemented as necessary to ensure the loss of reflexive responses. After midline laparotomy, the lungs were removed and placed in KrebsRinger bicarbonate buffer, containing $118 \mathrm{mM} \mathrm{NaCl}, 4.7 \mathrm{mM}$ $\mathrm{KCl}, 2.5 \mathrm{mM} \mathrm{CaCl}_{2}, 1.2 \mathrm{mM} \mathrm{KH}_{2} \mathrm{PO}_{4}, 1.2 \mathrm{mM} \mathrm{MgSO}_{4}, 24.2 \mathrm{mM}$ $\mathrm{NaHCO}_{3}$, and $10 \mathrm{mM}$ a-D-glucose (pH 7.4), equilibrated with $5 \%$ $\mathrm{CO}_{2} / 95 \% \mathrm{O}_{2}$, and maintained at $37^{\circ} \mathrm{C}$. Blood and other tissue materials were removed from the isolated lungs, weighed immediately, and snap-frozen in liquid nitrogen. 


\section{Determination of Cerium Content in the Lungs}

Cerium content in the lungs was estimated by induction coupled plasma-mass spectrometry (ICP-MS) at Elemental Analysis, Inc. (Lexington, KY, USA) according to standard protocols as described elsewhere [16]. The cerium concentration was estimated for the 1, 3, 14, 28, and 90-day post-exposure groups. Briefly, lung samples ( $n=4$ for each group) were prepared using the Environmental Protection Agency method 3050B for the analysis of total cerium by ICP-MS. Samples was weighed and digested with concentrated nitric acid, concentrated hydrochloric acid, and $30 \%$ hydrogen peroxide. Samples were diluted and compared against a laboratory control sample using an Agilent 7500cx ICPMS machine (Agilent Technologies, Santa Clara, CA, USA).

\section{Histopathological Examination}

Histopathological examination was performed on lungs from the day 1 saline control group, and in groups that had been exposed to $\mathrm{CeO}_{2}$ for $1,3,14$, and 28 days, using hematoxylin-eosin (H\&E) staining on formalin-fixed lung tissues. Using standard histopathological techniques lung tissues were embedded in paraffin wax, sectioned at $5 \mu \mathrm{m}$, mounted on glass slides, and stained with H\&E. In a blinded fashion, sections were examined by light microscopy by a board-certified pathologist.

\section{Immunoblotting Analysis}

Portions of individual lung tissues (100 to $150 \mathrm{mg}$ ) were homogenized in lysis buffer (T-PER, $8 \mathrm{~mL} / \mathrm{g}$ of tissue; Pierce, Rockford, IL, USA) containing phosphatase inhibitors (Sigma-Aldrich) and protease (Sigma-Aldrich). Tissue homogenates were sonicated for three cycles for 30 seconds at $150 \mathrm{~W}$. The supernatant protein was collected by centrifuging the tissue homogenate at $12000 \times \mathrm{g}$ for five minutes at $4^{\circ} \mathrm{C}$. The protein concentration of homogenates was determined via the $660-\mathrm{nm}$ assay method (Fisher Scientific, Rockford, IL, USA). Equal concentrations of the protein samples were prepared from individual animals by adding equal quantities of Laemmli $2 \mathrm{X}$ sample buffer (Sigma-Aldrich) and adjusting the protein concentration with the T-PER lysis buffer. Immunoblotting was performed on the prepared samples as described in Kakarla et al. [18] using the primary antibodies against caspase-3 (1:1000 dilution in 5\% bovine serum albumin [BSA] in TBST) (\#9662), cleaved caspase-3 (1:500 dilution in 5\% BSA in TBST) (\#9661S), Bax (1:1000 dilution in 5\% BSA in TBST) (\#2772), Bcl2 (1:1000 dilution in 5\% BSA in TBST) (\#2870S), caspase-9 (1:1000 dilution in 5\% BSA in TBST) (\#9506),
ERK-1/2 Thr 202/Tyr204 (1:1000 dilution in 5\% BSA in TBST) (\#9106S), phosphorylated ERK-1/2 (1:1000 dilution in 5\% BSA in TBST) Thr 202/Tyr204 (\#4377S), JNK (1:500 dilution in 5\% BSA in TBST) (\#9252), phosphorylated JNK Thr 183/Tyr185 (1:500 dilution in 5\% BSA in TBST) (\#9251S), p38 MAPK (1:1000 dilution in 5\% BSA in TBST) (\#9212), phosphorylated p38 MAPK Thr 180/ Tyr 182 (1:1000 dilution in 5\% BSA in TBST) (\#9216L), JAK-2 (1:1000 dilution in 5\% BSA in TBST) (\#3229), phosphorylated JAK-2 Tyr 1007/100 (1:1000 dilution in 5\% BSA in TBST) (\#3776), STAT-3 (1:500 dilution in 5\% BSA in TBST) (\#9132), and phosphorylated STAT-3 Tyr 705 (1:500 dilution in 5\% BSA in TBST) (\#9131S) were purchased from Cell Signaling Technology (Beverly, MA, USA).

\section{Data Analysis}

Data were analyzed using the SigmaPlot version 11.0 (Systat Software Inc., San Jose, CA, USA). Results are presented as mean \pm standard error of the mean. To determine overall comparisons one-way analysis of variance and two-way analysis of variance were performed, followed by a Student-Newman-Keuls post hoc test to determine differences between groups. A $p$-value $<0.05$ was considered statistically significant.

\section{RESULTS}

\section{Nanoparticle Characterization}

Similar to previous research $[12,16]$ using $\mathrm{CeO}_{2}$ nanoparticles made to the same specifications, the analysis of nanoparticle size by scanning electron microscopy and transmission electron microscopy confirmed the presence of single and agglomerated $\mathrm{CeO}_{2}$ nanoparticles in the suspension. Field emission scanning electron microscopy showed submicron groups dispersion of $\mathrm{CeO}_{2}$ nanoparticles with an average size of $9.26 \pm$ $0.58 \mathrm{~nm}$. Determination of the diameter of the primary $\mathrm{CeO}_{2}$ particles was $10.14 \pm 0.76 \mathrm{~nm}$ when evaluated by transmission electron microscopy.

\section{Accumulation of Cerium in the Lung Over Time After Exposure}

The concentration of cerium in the lungs was estimated using ICP-MS (Elemental Analysis). The concentration of cerium in the lungs decreased as post-exposure time increased. The concentration of cerium in lung tissue at 14,28 , and 90 days post-exposure was significantly lower than in tissue obtained one day after exposure to $\mathrm{CeO}_{2}$ nanoparticles, as shown in Figure 1. 
Exposure to Cerium Oxide Nanoparticles Alters the Gross Histological Appearance of the Lung Alterations in the appearance of the lungs following exposure included the presence of areas of black discoloration and white pustular nodules on the surface of the lungs, which appeared to increase over time (Figure 2). Histological alterations included an increased number of alveolar macrophages, an increased number of polymorphonuclear cells, and an apparent accumulation of particulate material in the alveolar spaces (Figure 3).

\section{Cerium Oxide Nanoparticles Increase Apoptotic} Protein Signaling in the Lung

Compared to the day 1 saline control group, the Bax to Bcl-2

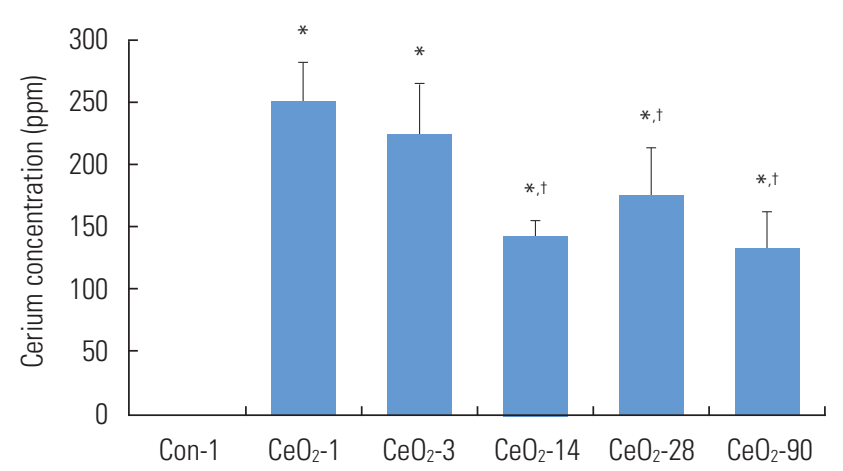

Figure 1. Cerium concentration in the lungs appears to diminish over time. Lung tissues (approximately $1 \mathrm{~g}$ ) were used for estimation of the cerium content in the lungs through induction couple plasma-mass spectrometry analysis. Con-1 represents the day 1 saline control group, while $\mathrm{CeO}_{2}-1,3,14,28$, and 90 represent the groups exposed to cerium oxide $\left(\mathrm{CeO}_{2}\right)$ nanoparticles for 1, 3, 14, 28, and 90 days respectively. One-way analysis of variance was performed for overall comparisons, while the Student-Newman-Keuls post hoc test was used to determine differences between groups. ${ }^{*} p<0.05$ between the day 1 saline control group, ${ }^{+} p<0.05$ between the $\mathrm{CeO}_{2}$ day 1 group. ratio in exposed animals was $99 \%$ higher three days after exposure $(p<0.05)$ before declining thereafter. Compared to the day 1 saline control group, the Bax to $\mathrm{BCl}-2$ ratio was 37,23 , and $14 \%$ lower at days 14,28 , and 56 , respectively, in animals ex-
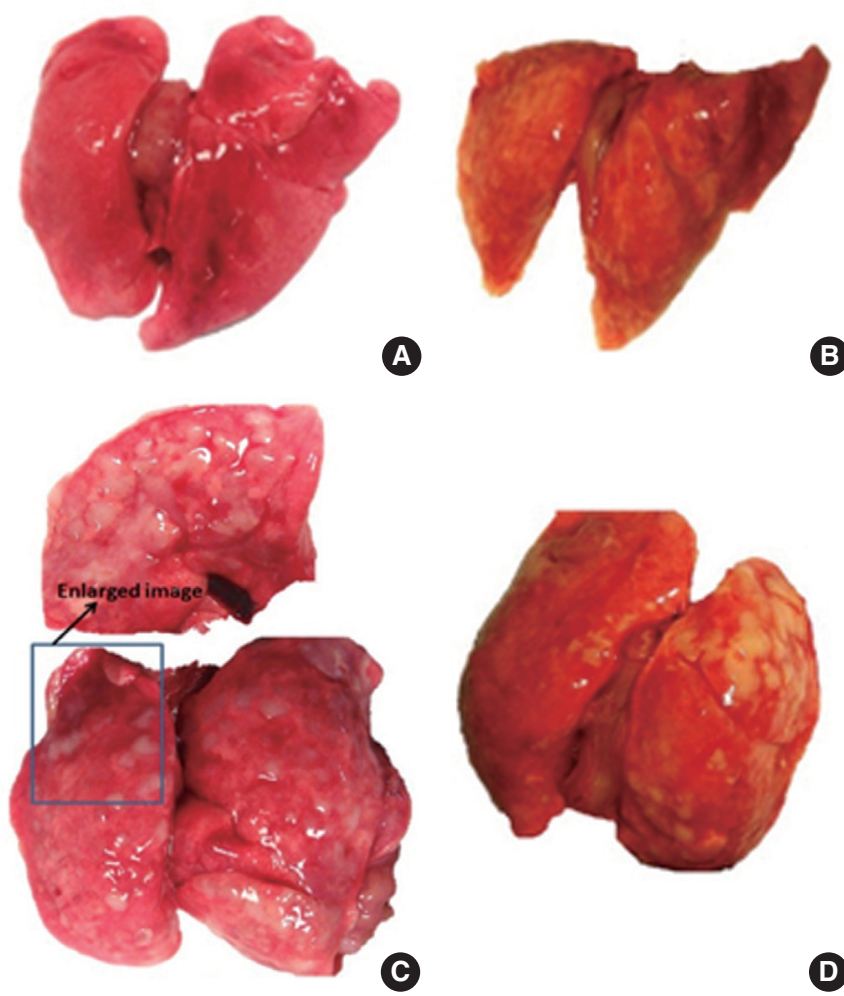

c

(D)

Figure 2. Gross alterations in the lungs with exposure to cerium oxide $\left(\mathrm{CeO}_{2}\right)$ nanoparticles include increased weight, black discoloration of the lungs, and the appearance of white nodules on the surface. The white nodules appeared to increase with longer exposure, and the white nodules appeared to coalesce to form bigger nodules at day 90 . (A) Saline control lungs day 1 , (B) $\mathrm{CeO}_{2}$ exposed lungs $(7.0 \mathrm{mg} / \mathrm{kg}$ ) day 28 , (C) $\mathrm{CeO}_{2}$ exposed lungs $\left(7.0 \mathrm{mg} / \mathrm{kg}\right.$ ) day 56 , and (D) $\mathrm{CeO}_{2}$ exposed lungs $(7.0 \mathrm{mg} / \mathrm{kg})$ day 90 .
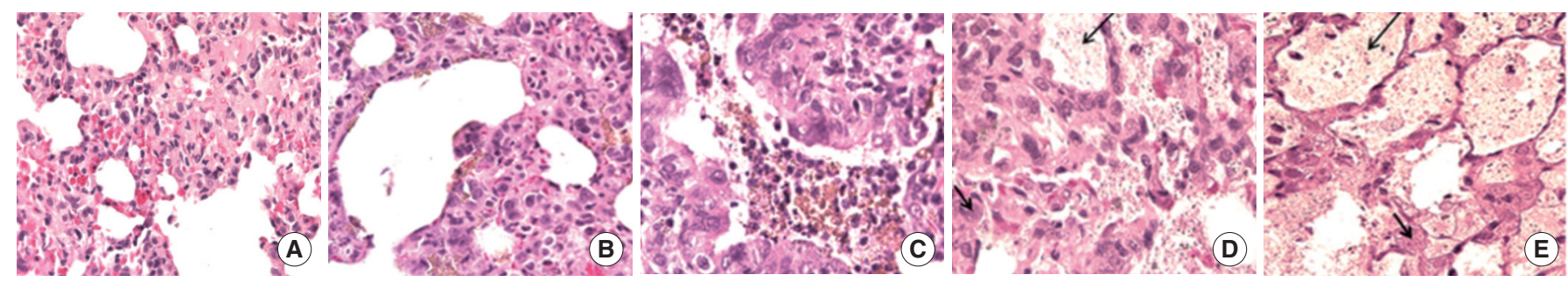

Figure 3. Alterations in the histological appearance of lungs associated with the instillation of $\mathrm{CeO}_{2}$ nanoparticles include an increased number of alveolar macrophages, an increase in the number of polymorphonuclear white blood cells (short arrow), and the increased accumulation of particulate matter (long arrow) in the air spaces (400X). (A) Saline control-1 H\&E lung 400X, (B) $\mathrm{CeO}_{2}-1 \mathrm{H} \& \mathrm{E}$ lung 400X, (C) $\mathrm{CeO}_{2}-3 \mathrm{H} \& \mathrm{E}$ lung 400X, (D) $\mathrm{CeO}_{2}-14 \mathrm{H} \& \mathrm{E}$ lung 400X, and (E) $\mathrm{CeO}_{2}-28 \mathrm{H} \& \mathrm{E}$ lung $400 \mathrm{X}$. $\mathrm{CeO}_{2}$, cerium oxide; $\mathrm{H} \& \mathrm{E}$, hematoxylin and eosin; $\mathrm{CeO}_{2}-\mathrm{n}$, lung tissues from the groups that had been exposed to $\mathrm{CeO}_{2}$ nanoparticles for $\mathrm{n}$ days. 

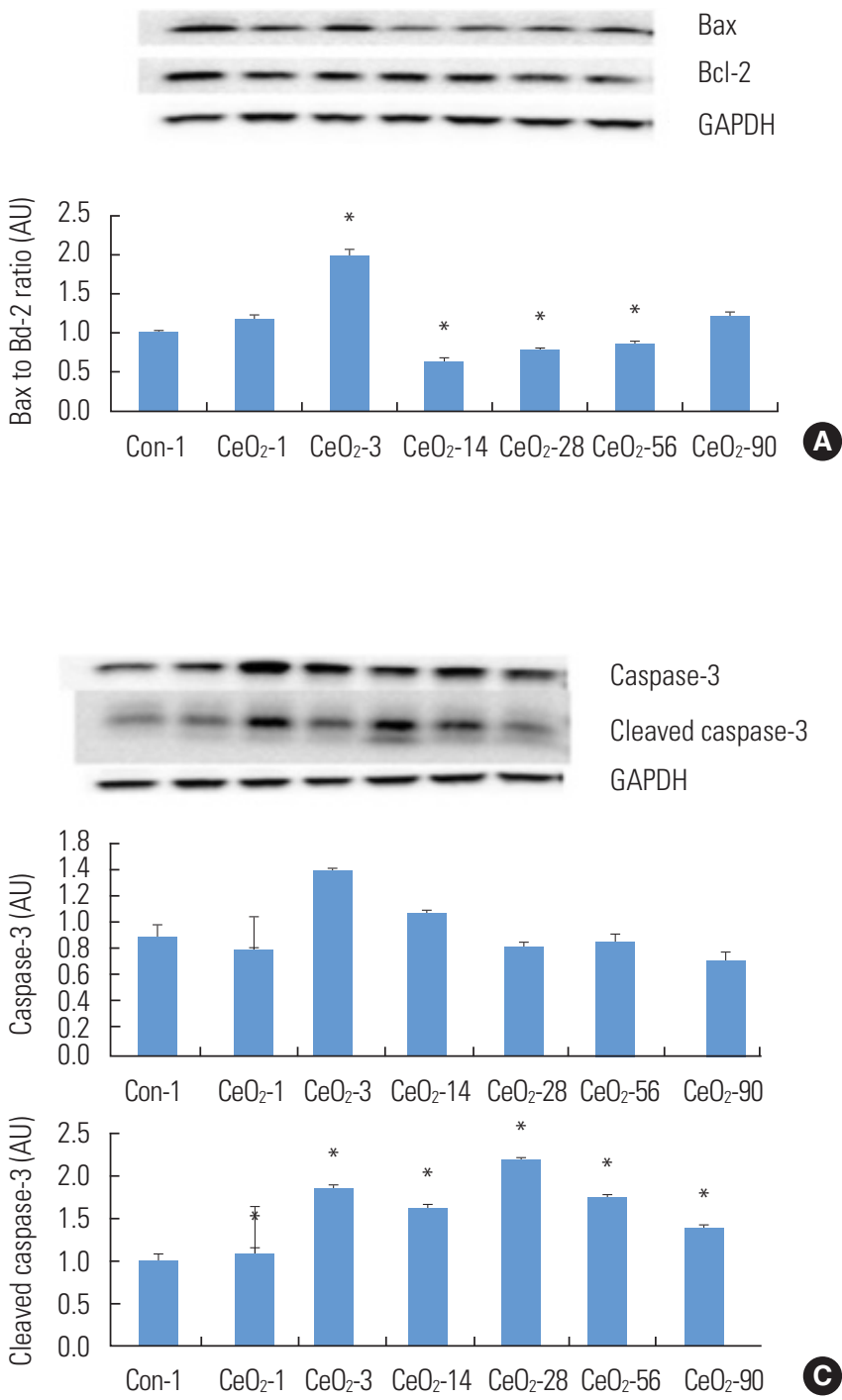

posed to $\mathrm{CeO}_{2}$ nanoparticles $(p<0.05)$ (Figure 4).

In order to extend these findings, we next examined the regulation of the initiator (caspase-9) and the executor caspases (caspase-3) [18]. Compared to the day 1 saline control group, the total caspase- 9 protein levels were reduced by $28,6,23,21$, and $32 \%$ in the $1,3,14,56$, and 90 -day post-exposure groups $(p<0.05)$. Compared to the day 1 saline control group, the expression of the $38-\mathrm{kDa}$ and $40-\mathrm{kDa}$ cleaved fragments of caspase- 9 was increased by $20 \%$ in the 3,14 , and 28 -day post-exposure groups $(p<0.05)$ (Figure 4$)$.

Caspase- 3 protein expression levels increased by $56 \%$ $(p<0.05)$ and $20 \%(p<0.05)$ in the 3 and 14-day exposure groups, when compared to the day 1 saline control group. Compared to the day 1 saline control group, the protein expression of the cleaved fragments of caspase-3 (17 kDa and $19 \mathrm{kDa}$ ) were increased by $10,88,66,119,77$, and $39 \%$ in the $1,3,14$,
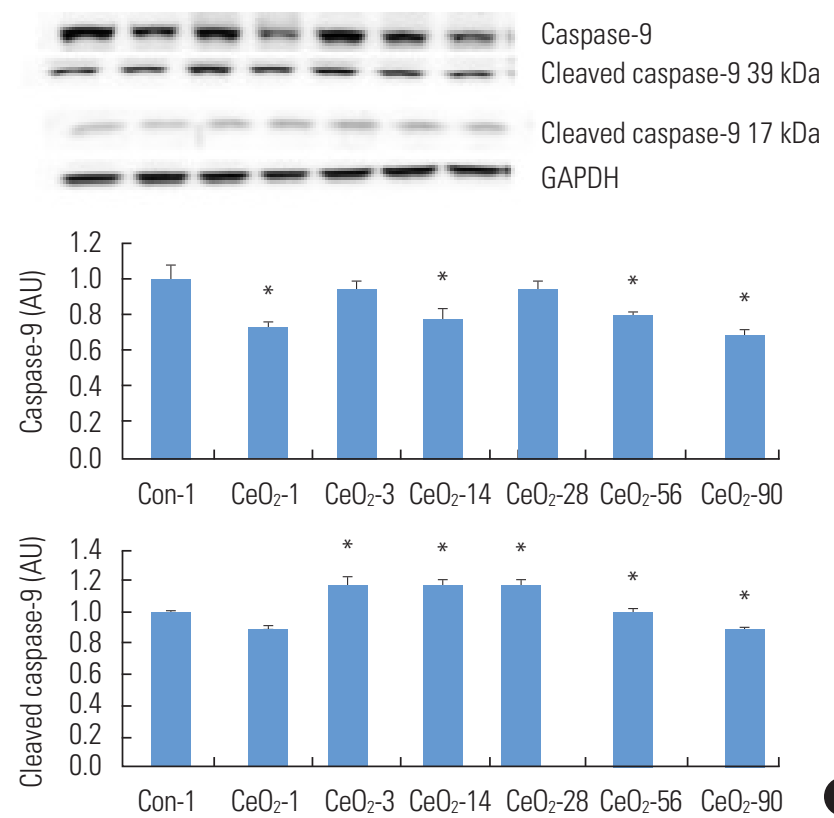

B

Figure 4. Cerium oxide $\left(\mathrm{CeO}_{2}\right)$ nanoparticles increase proapoptotic protein signaling in the lungs. Protein bands of the Bax, Bcl-2 (A), caspase-9, cleaved caspase-9 (B), and caspase-3, cleaved caspase-3 (C) proteins, along with the corresponding glyceraldehyde 3-phosphate dehydrogenase (GAP$\mathrm{DH}$ ) levels, are represented in the figure. Bands corresponding to the $\mathrm{X}$-axis labels are shown in the immunoblotting images. The protein levels were adjusted depending on the GAPDH levels and compared with the day 1 control group. One-way analysis of variance was performed for overall comparisons, while the Student-Newman-Keuls post hoc test was used to determine differences between groups. * $p<0.05$ between the day 1 saline control group.

28,56 , and 90 -day post-exposure groups $(p<0.05)$ (Figure 4).

\section{Cerium Oxide Nanoparticle Exposure Is Associ- ated With Activation of Mitogen-activated Pro- tein Kinase Signaling}

Compared to the day 1 saline control group, the ratio of phosphorylated p38 MAPK (Thr180/Tyr182) to total p38 MAPK was reduced by 22 and $14 \%$ in the day 1 and day 3 post-exposure groups $(p<0.05)$. However, this ratio was elevated by 52,15 , and $10 \%$ in the 14,28 , and 56 -day post-exposure groups, before it declined by $19 \%$ in the 90 -day post-exposure group $(p<0.05)$ (Figure 5).

The ratio of phosphorylated ERK-1/2 (Thr202/Tyr204) to total ERK- $1 / 2$ was reduced by $43,57,56,62,53$, and $41 \%$ in the 1,3 , $14,28,56$, and 90 -day post-exposure groups compared to the day 1 saline control group $(p<0.05)$ (Figure 5$)$. In contrast, the 

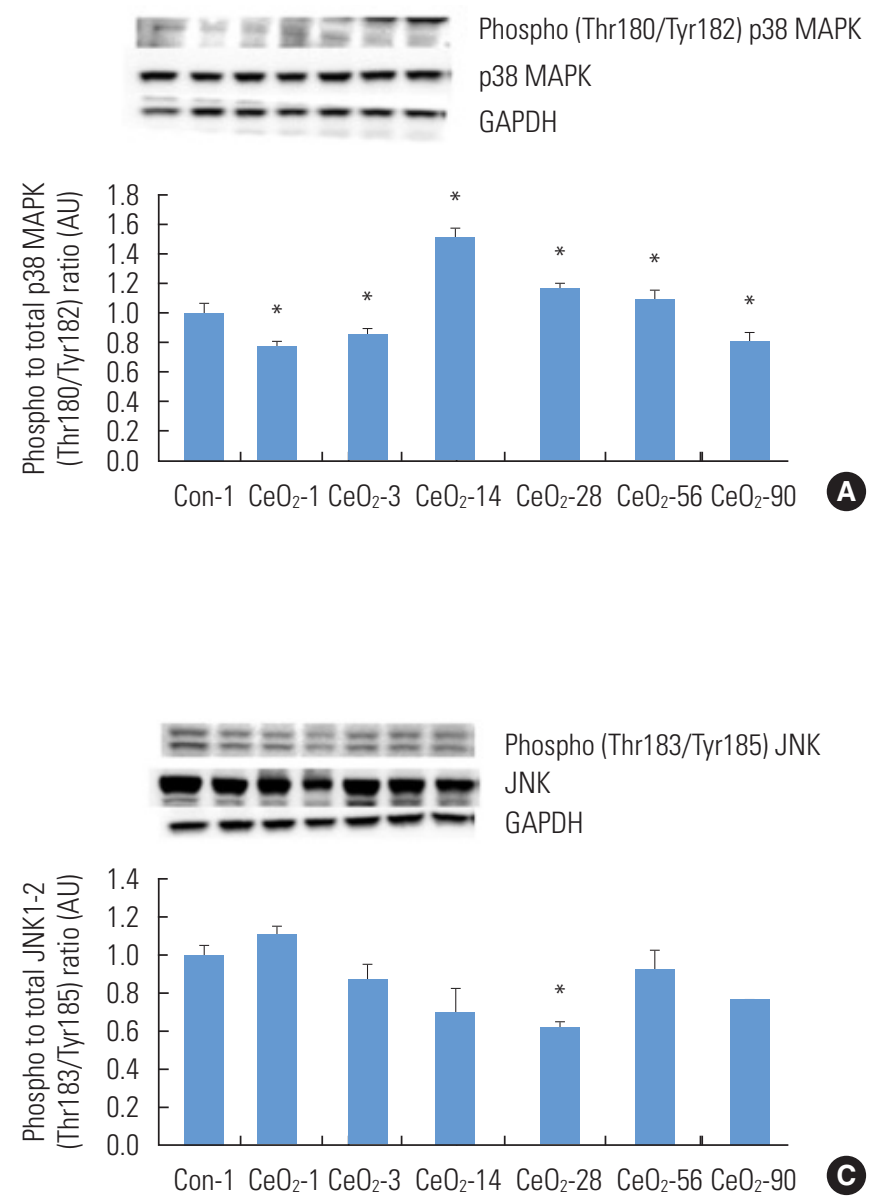

ratio of phosphorylated (Thr183/Tyr185) JNK to total JNK was unaltered following nanoparticle exposure (Figure 5).

\section{Cerium Oxide Nanoparticles Activate Inflamma-} tory Protein Signaling Through p38 MAPK Mediated STAT-3 Activation

It is known that JAK-2 and STAT-3 play a crucial role in inflammation [19]. When compared to the day 1 saline control group, the ratio of phosphorylated (Tyr705) to total STAT-3 protein was 111,193 , and $106 \%$ higher at 3, 14, and 28 days after exposure $(p<0.05)$ (Figure 6). The ratio of phosphorylated (Tyr1007/1008) JAK-2 to total JAK-2 was 25 and $103 \%$ higher in the 1 and 90 day post-exposure groups compared to the control animals ( $p<$ 0.05) (Figure 6).

\section{DISCUSSION}

Previous In vitro and in vivo studies have suggested that exposure to $\mathrm{CeO}_{2}$ nanoparticles can elicit toxic effects, although the underlying mechanism is not well understood $[3,8,12,20]$.
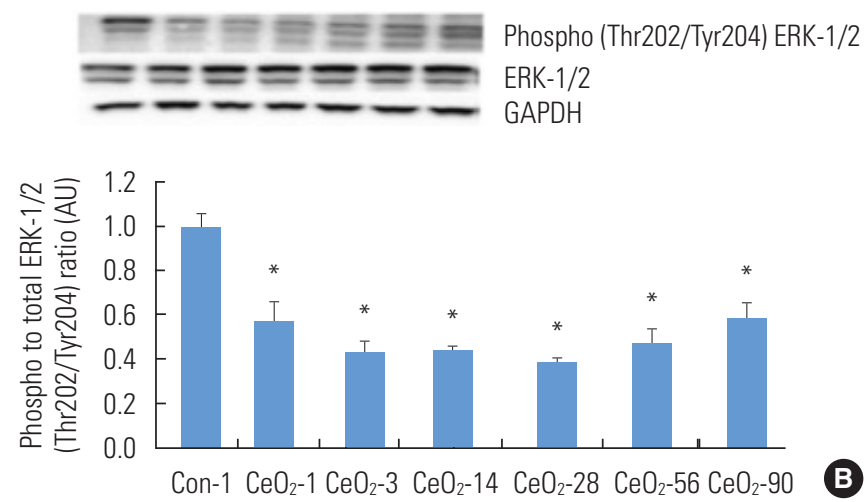

Figure 5. Activation of mitogen-activated protein kinase (MAPK) protein signaling was observed with the instillation of cerium oxide $\left(\mathrm{CeO}_{2}\right)$ nanoparticles. Protein bands of the p38 MAPK, phosphorylated p38 MAPK (A), ERK-1/2-MAPK, phosphorylated ERK-1/2-MAPK (B), and JNK, phosphorylated JNK (C) proteins, along with the corresponding glyceraldehyde 3-phosphate dehydrogenase (GAPDH) levels are represented in the figure bands corresponding to the X-axis labels and are shown in the immunoblotting images. Protein levels were adjusted according to the GAPDH levels and compared with the day 1 control group. One-way analysis of variance was performed for overall comparisons, while the Student-NewmanKeuls post hoc test was used to determine differences between groups. ${ }^{*} p<0.05$ between the day 1 saline control group.

The primary finding of the current study is that pulmonary exposure to $\mathrm{CeO}_{2}$ nanoparticles is associated with histological evidence of lung inflammation, the activation of MAPK signaling, the phosphorylation of STAT-3, increased caspase-3 cleavage, and inflammation.

The data from the current study show that the instillation of $\mathrm{CeO}_{2}$ nanoparticles leads to the deposition of cerium in the lungs, as shown by ICP-MS (Figure 1). We also observed that exposure to $\mathrm{CeO}_{2}$ nanoparticles was associated with the development of white nodular structures on the lung surface (Table 1, Figures 2 and 3). Recent work has shown that nanoparticles such as carbon nanotubes, titanium dioxide nanoparticles, and polyacrylate nanoparticles can induce granulomas on the lung surface [21-23]. It is possible that the white nodules we observed in the present study may be the byproduct of an ongoing inflammatory reaction, which could result in either the clearance of the nanoparticles or their further development into granulomas on the surface of the lungs $[22,24]$. The aforementioned possibility is consistent with our histopathological analysis, in which we observed an increase in the number of al- 
Table 1. Cerium oxide $\left(\mathrm{CeO}_{2}\right)$ nanoparticle exposure increases the ratio of lung weight to body weight

\begin{tabular}{|c|c|c|c|c|}
\hline \multirow{2}{*}{ Exposure (d) } & \multicolumn{2}{|c|}{ Body weight (g) } & \multicolumn{2}{|c|}{ Lung weight (g) } \\
\hline & Saline control & $\mathrm{CeO}_{2}(7.0 \mathrm{mg} / \mathrm{kg})$ & Saline control & $\mathrm{CeO}_{2}(7.0 \mathrm{mg} / \mathrm{kg})$ \\
\hline 1 & $319.67 \pm 15.92$ & $319.67 \pm 15.20$ & $1.74 \pm 0.28$ & $1.88 \pm 0.08$ \\
\hline 3 & $310.33 \pm 28.10$ & $331.67 \pm 24.00$ & $1.54 \pm 0.27$ & $2.19 \pm 0.15$ \\
\hline 14 & $345.67 \pm 27.11$ & $332.33 \pm 21.07$ & $1.90 \pm 0.31$ & $2.12 \pm 0.23$ \\
\hline 28 & $411.33 \pm 29.2^{1,3}$ & $403.67 \pm 28.94^{1,3}$ & $1.82 \pm 0.09$ & $2.43 \pm 0.30$ \\
\hline 56 & $451.67 \pm 26.21^{1-3}$ & $451.00 \pm 34.6^{1-4}$ & $1.56 \pm 0.24$ & $2.84 \pm 0.58$ \\
\hline 90 & $523.33 \pm 60.87^{1-5}$ & $519.33 \pm 44.84^{1-5}$ & $1.62 \pm 0.11$ & $2.75 \pm 0.51$ \\
\hline
\end{tabular}

Lung tissues were collected from groups of animals that were intratracheally instilled with either normal saline or $\mathrm{CeO}_{2}$ nanoparticles at a dosage of $7.0 \mathrm{mg} / \mathrm{kg}$, at $1,3,14,28,56$, and 90 days after exposure. The lung tissues were cleaned to remove blood and tissue debris with Krebs's lactate solution and weighed immediately ( $n=6 /$ group). Two-way analysis of variance was performed for overall comparisons, while the Student-Newman-Keuls post hoc test was used to determine differences between groups; $p<0.05$ were considered to indicate statistical significance.

${ }^{1}$ Significantly different from the one-day exposure group for a given condition.

${ }^{2}$ Significantly different from the three-day exposure group for a given condition.

${ }^{3}$ Significantly different from the 14-day exposure group for a given condition.

${ }^{4}$ Significantly different from the 28-day exposure group.

${ }^{5}$ Significantly different from the 56-day exposure group.

veolar macrophages and polymorphonuclear white blood cells in the lungs of animals that had been exposed to $\mathrm{CeO}_{2}$ nanoparticles. It is thought that the toxic effects of most nanoparticles (silver, silica, titanium dioxide, zinc oxide, and carbonaceous nanoparticles) are characterized by increased oxidative stress [25-29]. Whether these increases in oxidative stress are due to increased reactive oxygen species (ROS) generation or decreased ROS scavenging is currently unclear, although many metallic oxide nanoparticles have been shown to increase ROS production $[30,31]$.

Increased ROS levels may also induce apoptotic signaling. We observed an increase in the pro-apoptotic Bax to $\mathrm{BCl}-2$ ratio at one and three days after the exposure to $\mathrm{CeO}_{2}$ nanoparticles, with a subsequent decline. Since the $\mathrm{Bax}$ to $\mathrm{BCl}-2$ ratio is an indicator of whether a cell is likely to undergo apoptosis [18,32], we next examined the possibility that $\mathrm{CeO}_{2}$ nanoparticle exposure may be associated with the activation of caspase-3. Consistent with the $\mathrm{Bax} / \mathrm{BCl}-2$ data, we found that caspase-3 cleavage (activation) was elevated at $3,14,28$, and 56 days post-exposure. Why caspase- 3 cleavage was present in the absence of an elevated $\mathrm{Bax} / \mathrm{BCl}-2$ ratio is currently unclear. Other signaling pathways (extrinsic or intrinsic pathways) that activate the apoptotic pathway may be in play and explain the possible activation of effector caspase- 3 in the absence of an elevated $\mathrm{Bax} / \mathrm{BCl}-2$ ratio. It is thought that mild lung injury may elicit the repair of the damaged tissue, whereas excessive apoptosis-induced cell death may lead to the development of lung remodeling and fibrosis [33]. Bearing this in mind, the activation of caspase- 3 we identified in the current study may help to ex- plain previous findings that increased lung fibrosis follows exposure to $\mathrm{CeO}_{2}$ nanoparticles [12].

MAPKs are stress-responsive proteins that can be activated by growth factors, chemicals, ultraviolet radiation, heat, synthesis inhibitors, metals, or foreign organisms [34]. MAPK pathways have been shown to play important roles in oxidative stress and inflammation induced by nanoparticles and metals $[15,31]$. The three primary members of the MAPK signaling modules are the $\mathrm{p} 38$, JNK, and ERK-1/2 MAPKs. MAPK proteins are thought to phosphorylate (activate) transcription factors that are involved in regulating both cell survival and cell death. In the present study, exposure to $\mathrm{CeO}_{2}$ nanoparticles was associated with increased phosphorylation of p38 MAPK at 14, 28, and 56 days after exposure. Conversely, we found that ERK1/2-MAPK activity appeared to be impaired by $\mathrm{CeO}_{2}$ nanoparticles (Figure 5). Since ERK-1/2-MAPK is thought to play an important role in cell survival and p38 MAPK may play an important role in apoptosis [34], these differences in MAPK signaling may help to explain the sustained caspase-3 cleavage after the pro-apoptotic Bax to $\mathrm{BCl}-2$ ratio returned to normal.

It is well known that nanoparticle exposure is often associated with increased levels of cytokines, interleukins, and other mediators of inflammation. The Janus kinase/signal transducers and activators of transcription (JAK/STAT) pathway is a particularly important pathway in mediating inflammation [19]. Interestingly, JAK-2 did not appear to play an important role in the toxicological response, as its phosphorylation (Tyr1007/ 1008) was elevated only at day 1 and day 90 (Figure 6). Conversely, the phosphorylation of STAT-3 (Tyr705) seemed to 

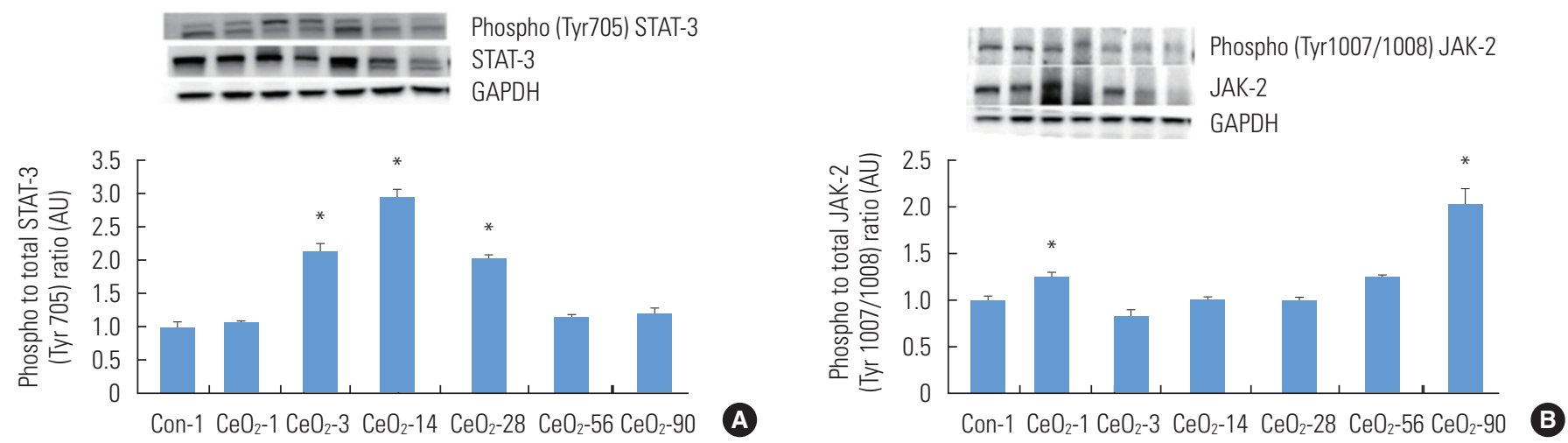

Figure 6. Activation of STAT-3 after exposure to cerium oxide $\left(\mathrm{CeO}_{2}\right)$ nanoparticles follows the activation of p38 MAPK. The protein bands of the STAT-3, phosphorylated STAT-3 (A) and JAK-2, phosphorylated JAK-2 (B) proteins, along with the corresponding glyceraldehyde 3-phosphate and dehydrogenase (GAPDH) values, are represented in the figure. The bands corresponding to the X-axis labels are shown in the immunoblotting images. The protein levels were adjusted according to the GAPDH levels and compared with the day 1 control. One-way analysis of variance was performed for overall comparisons, while the Student-Newman-Keuls post hoc test was used to determine differences between groups. ${ }^{*} p<0.05$ between the day 1 saline control group.

parallel p38 MAPK activation (Figure 6). A previous study has demonstrated that p38 MAPK can act as an upstream activator of STAT-3, which, in turn, can induce apoptosis when activated [35]. Other research has shown that the p38 MAPK and STAT-3 signaling pathways can work in concert or separately to exert apoptotic effects on the cells [36]. These data, considered in light of our findings regarding the increased Bax to $\mathrm{BCl}-$ 2 ratio, are consistent with the possibility that apoptosis mediated by $\mathrm{CeO}_{2}$ nanoparticles is mediated through the activation of the $\mathrm{P} 38$ MAPK and STAT-3 signaling pathways.

In summary, our data suggest that lung exposure to $\mathrm{CeO}_{2}$ nanoparticles is associated with the increased accumulation of cerium in the lungs and gross pathological and histological alterations to the lungs. It also appears that $\mathrm{CeO}_{2}$ nanoparticles can induce inflammation and apoptotic protein signaling in the lungs. Overall, the data from the current study indicate that $\mathrm{CeO}_{2}$ nanoparticle-induced inflammation and apoptosis may be mediated through the activation of the stress-responsive MAPK protein signaling pathway, the phosphorylation of STAT-3, and the activation of the intrinsic apoptosis pathway (Figure 6). Given these findings, additional research to evaluate the role of subcellular organelles in inducing apoptosis in these conditions is likely warranted.

\section{CONFLICT OF INTEREST}

The authors have no conflicts of interest with the material presented in this paper.

\section{REFERENCES}

1. Heckert EG, Seal S, Self WT. Fenton-like reaction catalyzed by the rare earth inner transition metal cerium. Environ Sci Technol 2008;42(13):5014-5019.

2. Bumajdad A, Eastoe J, Mathew A. Cerium oxide nanoparticles prepared in self-assembled systems. Adv Colloid Interface Sci 2009;147-148:56-66.

3. Park B, Martin P, Harris C, Guest R, Whittingham A, Jenkinson P, et al. Initial in vitro screening approach to investigate the potential health and environmental hazards of Enviroxtrade mark - a nanoparticulate cerium oxide diesel fuel additive. Part Fibre Toxicol 2007;4:12.

4. Karakoti AS, Monteiro-Riviere NA, Aggarwal R, Davis JP, Narayan RJ, Self WT, et al. Nanoceria as antioxidant: synthesis and biomedical applications. JOM (1989) 2008;60(3):33-37.

5. Niu J, Azfer A, Rogers LM, Wang X, Kolattukudy PE. Cardioprotective effects of cerium oxide nanoparticles in a transgenic murine model of cardiomyopathy. Cardiovasc Res 2007;73(3): 549-559.

6. Das M, Patil S, Bhargava N, Kang JF, Riedel LM, Seal S, et al. Auto-catalytic ceria nanoparticles offer neuroprotection to adult rat spinal cord neurons. Biomaterials 2007;28(10):1918-1925.

7. Colon J, Herrera L, Smith J, Patil S, Komanski C, Kupelian P, et al. Protection from radiation-induced pneumonitis using cerium oxide nanoparticles. Nanomedicine 2009;5(2):225-231.

8. Lin W, Huang YW, Zhou XD, Ma Y. Toxicity of cerium oxide nanoparticles in human lung cancer cells. Int J Toxicol 2006; 
25(6):451-457.

9. Eom $\mathrm{HJ}$, Choi J. Oxidative stress of $\mathrm{CeO}_{2}$ nanoparticles via p38Nrf-2 signaling pathway in human bronchial epithelial cell, Beas-2B. Toxicol Lett 2009;187(2):77-83.

10. He X, Zhang H, Ma Y, Bai W, Zhang Z, Lu K, et al. Lung deposition and extrapulmonary translocation of nano-ceria after intratracheal instillation.Nanotechnology 2010;21(28):285103.

11. Cassee FR, van Balen EC, Singh C, Green D, Muijser H, Weinstein $J$, et al. Exposure, health and ecological effects review of engineered nanoscale cerium and cerium oxide associated with its use as a fuel additive. Crit Rev Toxicol 2011;41(3):213-229.

12. Ma JY, Zhao H, Mercer RR, Barger M, Rao M, Meighan T, et al. Cerium oxide nanoparticle-induced pulmonary inflammation and alveolar macrophage functional change in rats. Nanotoxicology 2011;5(3):312-325.

13. Guyton KZ, Liu Y, Gorospe M, Xu Q, Holbrook NJ. Activation of mitogen-activated protein kinase by $\mathrm{H} 2 \mathrm{O} 2$. Role in cell survival following oxidant injury. J Biol Chem 1996;271(8):4138-4142.

14. Tournier C, Thomas G, Pierre J, Jacquemin C, Pierre M, Saunier B. Mediation by arachidonic acid metabolites of the H2O2-induced stimulation of mitogen-activated protein kinases (extracellular-signal-regulated kinase and c-Jun NH2-terminal kinase). Eur J Biochem 1997;244(2):587-595.

15. Samet JM, Graves LM, Quay J, Dailey LA, Devlin RB, Ghio AJ, et al. Activation of MAPKs in human bronchial epithelial cells exposed to metals. Am J Physiol 1998;275(3 Pt 1):L551-L558.

16. Nalabotu SK, Kolli MB, Triest WE, Ma JY, Manne ND, Katta A, et al. Intratracheal instillation of cerium oxide nanoparticles induces hepatic toxicity in male Sprague-Dawley rats. Int J Nanomedicine 2011;6:2327-2335.

17. Ma JY, Zhao H, Mercer RR, Barger M, Rao M, Meighan T, et al. Cerium oxide nanoparticle-induced pulmonary inflammation and alveolar macrophage functional change in rats. Nanotoxicology 2011;5(3):312-325.

18. Wu M, Liu H, Fannin J, Katta A, Wang Y, Arvapalli RK, et al. Acetaminophen improves protein translational signaling in aged skeletal muscle. Rejuvenation Res 2010;13(5):571-579.

19. Kakarla SK, Fannin JC, Keshavarzian S, Katta A, Paturi S, Nalabotu SK, et al. Chronic acetaminophen attenuates age-associated increases in cardiac ROS and apoptosis in the Fischer Brown Norway rat. Basic Res Cardiol 2010;105(4):535-544.

20. Rawlings JS, Rosler KM, Harrison DA. The JAK/STAT signaling pathway. J Cell Sci 2004;117(Pt 8):1281-1283.

21. Park EJ, Choi J, Park YK, Park K. Oxidative stress induced by cerium oxide nanoparticles in cultured BEAS-2B cells. Toxicology
2008;245(1-2):90-100.

22. Donaldson K, Aitken R, Tran L, Stone V, Duffin R, Forrest G, et al. Carbon nanotubes: a review of their properties in relation to pulmonary toxicology and workplace safety. Toxicol Sci 2006; 92(1):5-22.

23. Park EJ, Yoon J, Choi K, Yi J, Park K. Induction of chronic inflammation in mice treated with titanium dioxide nanoparticles by intratracheal instillation. Toxicology 2009;260(1-3):37-46.

24. Ren $H$, Huang $X$. Polyacrylate nanoparticles: toxicity or new nanomedicine? Eur Respir J 2010;36(1):218-221.

25. Bergamaschi E, Bussolati O, Magrini A, Bottini M, Migliore L, Bellucci $S$, et al. Nanomaterials and lung toxicity: interactions with airways cells and relevance for occupational health risk assessment. Int J Immunopathol Pharmacol 2006;19(4 Suppl):3-10.

26. Stone V, Johnston $\mathrm{H}$, Clift MJ. Air pollution, ultrafine and nanoparticle toxicology: cellular and molecular interactions. IEEE Trans Nanobioscience 2007;6(4):331-340.

27. Folkmann JK, Risom L, Jacobsen NR, Wallin H, Loft S, Møller P. Oxidatively damaged DNA in rats exposed by oral gavage to C60 fullerenes and single-walled carbon nanotubes. Environ Health Perspect 2009;117(5):703-708.

28. Jeong YS, Oh WK, Kim S, Jang J. Cellular uptake, cytotoxicity, and ROS generation with silica/conducting polymer core/ shell nanospheres. Biomaterials 2011;32(29):7217-7225.

29. Koike E, Kobayashi T. Chemical and biological oxidative effects of carbon black nanoparticles. Chemosphere 2006;65(6): 946-951.

30. Li N, Xia T, Nel AE. The role of oxidative stress in ambient particulate matter-induced lung diseases and its implications in the toxicity of engineered nanoparticles. Free Radic Biol Med 2008;44(9):1689-1699.

31. Buzea C, Pacheco II, Robbie K. Nanomaterials and nanoparticles: sources and toxicity. Biointerphases 2007;2(4):MR17-MR71.

32. Marano F, Hussain S, Rodrigues-Lima F, Baeza-Squiban A, Boland S. Nanoparticles: molecular targets and cell signalling. Arch Toxicol 2011;85(7):733-741.

33. Lenaz $\mathrm{G}$. The mitochondrial production of reactive oxygen species: mechanisms and implications in human pathology. IUBMB Life 2001;52(3-5):159-164.

34. Kuwano K. Epithelial cell apoptosis and lung remodeling. Cell Mol Immunol 2007;4(6):419-429.

35. Kang KA, Wang ZH, Zhang R, Piao MJ, Kim KC, Kang SS, et al. Myricetin protects cells against oxidative stress-induced apoptosis via regulation of PI3K/Akt and MAPK signaling pathways. Int J Mol Sci 2010;11(11):4348-4360. 
Journal of

Preventive Medicine

\& Public Health

Cerium Oxide Nanoparticle Exposure Activates MAPK in Rat Lungs

36. Blank VC, Peña C, Roguin LP. STAT1, STAT3 and p38MAPK are interferon-alpha2b peptide. Exp Cell Res 2010;316(4):603-614. involved in the apoptotic effect induced by a chimeric cyclic 